\title{
Factors Militating against the control of Helminthosis in Livestock in developing countries
}

\author{
P H Bamaiyi \\ Department of Pathology and Microbiology \\ Faculty of Veterinary Medicine, Universiti Putra Malaysia \\ Email: phbamaiyi@yahoo.com; Tel: +60149655503 \\ Received: 18-06-2011, Accepted: 21-07-2011, Published Online: 17-11-2011 \\ doi: $10.5455 /$ vetworld.2012.42-47
}

\begin{abstract}
Helminthosis in livestock has been a problem from time immemorial. Local farmers have ancient methods of controlling helminth parasites which had limited applications and success. Modern methods of controlling helminths are more effective if properly and strategically administered in such a way as to ensure adequate control of helminths and at the least possible cost to the farmer. Many factors militate against the control of Helminthosis in developing countries. Some of these factors are the literacy level of farmers, government funding and problems associated with experts in the field who are supposed to be involved in the control of Helminthosis. In this review some solution is proffered against these factors so as to ensure maximum helminth control and greater productivity of livestock.
\end{abstract}

Key words: Factors, control, Helminthosis, livestock, developing countries

\section{Introduction}

Helminthosis is the disease caused by the presence of helminth parasites within the gastrointestinal tract of an individual. All species of animals can be infected with helminth parasites. The infection usually is more severe in the very young and the very old or immunocompromised individuals. Some adult animals can thrive fairly well while infected with some helminth parasites without showing obvious clinical signs while the vast majority suffer reduced productivity under heavy worm burdens. It appears some breeds of animals are more resistant to certain helminth parasites than others.

Helminthosis has been a long time standing problem militating against the production of livestock especially in the developing countries. It is one of the commonest infections of livestock that famers are very familiar with (Chavan, et al., 2008). It greatly affects economically the farmer and the nation (Tisdell, Harrison, \& Ramsay, 1999). Economic loses are in billions of dollars to the livestock industry of these nations as helminth infected animals are not able to perform to the optimum as the body struggles to cope with the burden of the helminth infection. The cost of treatment against helminth parasites in ruminants alone worldwide is estimated at $\$ 1.7$ billion annually (Lanusse \& Prichard, 1993).

The significance of Helminthosis has been recognized by livestock farmers right from the earliest of times and various methods have been employed by them to control helminths in their animals including the use of medicinal plants and herbs and different grazing techniques (Bukhari $\&$ Sanyal, 2011). The Fulani herdsmen in Nigeria for example start treating calves against helminths with medicinal plant as early as within a week of birth (Ibrahim, et.al., 1983) because they recognize the importance of helminths in calves of less than a year old. In many livestock species such as sheep gastrointestinal parasites are arguably the most important reasons for suboptimal productivity (Sargison, 2011).

In a desperate attempt to get rid of helminths from their livestock farmers have used all forms of treatment and control measures including incantations, holy books, hygiene, herd sharing, 
bush burning, local concoctions, self-diagnosis, herbs and chemotherapy (Adekunle, et.al., 2002; Tibbo, et.al., 2011).

The major control method employed against helminth parasites in developing countries as elsewhere is the use of chemotherapy (Aragaw, et.al., 2010; Sargison, 2011). Mostly broadspectrum anthelmintics such as the Benzimidazoles (administerd per os) and levamisole hydrochloride (administered per os, intramuscularly and subcutaneously) are used. Many other dewormers are employed regularly against helminths. This method is relatively effective compared to ancient traditional practices that were not scientific such as incantations and some herbs which were given without any knowledge of their dose rate, side effects or mechanism of action (Adekunle, et al., 2002; Tibbo, et al., 2011) but has been bedevilled with major constraints such as cost and a good knowledge of the epidemiology of the parasites concerned leading to abuse of the antihelminthics which also complicates the problem of parasitic resistance to some form of chemotherapy (Tembely, et al., 1997; Bukhari \& Sanyal, 2011). This implies that drugs are less effectively used and the economic loss suffered by farmers and national economies is little ameliorated. The solution to this problem is not as easy as it sounds due to the hydra-headed nature of the problem which involves the farmers, the governments in these nations, the veterinary and allied personnel and the developed countries that from time to time lend a helping hand in the control of helminth infections in the developing economies of the world.

The total eradication of most helminths from livestock is not practical and in some cases not even desirable as some of the parasites are necessary for conferring immunity on the host. The strategies for preventive control must involve stopping a build-up of large numbers of larvae on pasture and anticipation of periods for likely multiplication of larvae on pasture and to move animals from such pastures during those periods. In order to achieve this goal there has to be a multifaceted approach involving grazing management, use of anthelmintics and dependence on acquisition of immunity. A complete integration of these three gives the best efficient control measures (Brundson, 1980; Aragaw, et al., 2010; Bukhari \& Sanyal, 2011).

\section{Factors Militating against Helminth Control}

Many other factors militate against the control of Helminthosis in developing countries. These are discussed briefly below.

Poor Funding of anthelmintic campaigns: Strategic use of anthelmintics is designed to reduce worm burdens and contamination of pasture by helminth eggs. Strategic control with anthelmintic is based on knowledge of seasonal changes and epidemiology of the infection. For example, treatment against Haemonchus contortus can be done during the months when the infection is about beginning and repeated just before when it would have reached its peak which varies from country to country. To adequately carry out these strategic and tactical deworming program adequate funds should be provided by relevant government authorities. But these funds are not forth coming and hence farmers are left at the mercies of their pockets to get their animals dewormed (Bukhari \& Sanyal, 2011). Where such funds are even available many developing countries battle with the problem of endemic corruption which has hindered much needed speedy development.

I lliteracy: The problem of illiteracy has contended against the successful control of Helminthosis in developing countries. Most farmers cannot read or write and have little or no information on orthodox means of controlling Helminthosis hence resort to other means of improving the productivity of their animals including superstition. This lack or inadequate education also makes these farmers to stop experts from handling their animals (Esrony, et.al., 1997; Tembely, et al., 1997). The best forms of control of helminths will require a basic understanding of certain principles bordering on the parasite's developmental cycle, mode of transmission and predisposing factors to infection (Moore \& Chiodini, 2010; Roepstorff, 
et.al., 2011). Age of animals is also important in helminth control but some illiterate farmers will not understand this (Chitra, et.al., 2011). Most farmers in developing countries have little access to such basic information or are not interested. Therefore, they are not able to make use of such information for the control of helminths in their livestock.

Poverty: The cost of veterinary services is a major consideration for farmers in developing countries due to the low level of income (Reddy $\&$ Rao.B, 2011). The level of poverty in developing countries among farmers who keep these animals is alarmingly high and hence is a major drawback to their ability to employ the services of qualified veterinarians in controlling Helminthosis. Also, the high cost of modern anthelmintics has limited the effective control of these parasites (Tisdell, et al., 1999). Some farmers with large livestock size would prefer the services of a governmental veterinary personnel or a cooperative service that are mandated by agreement to offer such services. Farmers preference here is not based on expertize but based on affordability of the cost of treatment and though the private veterinarians may be more thorough and efficient in their approach but cost is a major consideration for the farmers and will determine who gets what and does what (P.Mirajkar, et.al., 2011).

Inadequate extension services: Since the illiteracy level is high among livestock farmers there is a greater need for extension workers and services but these are in short supply. Many farmers come across such workers only when there is a major epidemic that the government is trying to contain or the government is launching a vaccination campaign but few get to hear about control of Helminthosis from these workers who themselves are poorly informed or lack dedication and commitment to their work (Adekunle, et al., 2002).

I naccessible location of farmers: Many livestock farmers live in remote rural areas with either no accessible roads or very rough roads that take only the determined to reach there. Since the government has not provided adequate transport logistics to reach all these areas it becomes difficult for veterinary personnel to get across to them (Bukhari \& Sanyal, 2011).

Attitude of workers: The extension workers and unfortunately some veterinary personnel do not only lack dedication and commitment to their work but are driven by pecuniary avarice and greed to exploit these already impoverished livestock farmers for their selfish gains. Such attitudes also discourage farmers from employing the services of experts in curtailing disease (Adekunle, et al., 2002).

Nomadic nature of many farmers: Livestock farmers especially the cattle rearers live nomadic lives moving over long distances in search of pasture and water and sometimes running away from suspected disease infested locations. Sometimes they have to travel hundreds and thousands of kilometers in search of pasture. In the process of doing this they introduce more helminth infections in their new locations or aggravate the already existing infections (Tibbo, etal., 2011).

The activities of quacks: The activities of quacks have continued to be a major impediment not only to helminthosis but the control of disease generally in the developing countries. These quacks are unqualified individuals who take the advantage of the ignorance of farmers to administer wrong therapy to their animals. This has continued to hinder the successful control of disease (Adekunle, et al., 2002).

Substandard drugs and indiscriminate use of drugs: Our markets are flooded with all manner of substandard, fake and expired drugs which are used by farmers or unscrupulous elements (quacks) to control helminth infections leading to the problem of development of resistance to certain drugs due to under dosage or use of expired drugs. Currently many anthelmintics are present in the market whose potencies and efficacies have not been independently proven by any research but yet are being marketed for helminth control leading to failures in helminth control. In some cases widespread intensive use of sometimes low quality anthelmintics has led to development of 
resistance and hence a reduction in the usefulness of available anthelmintics (Reinecke, 1980;Donald, 1985; Schantz, 1987; Tibbo, et al., 2011).

Indiscriminate grazing: since farmers cannot afford to keep their animals intensively or give them adequate and balanced nutrition the animals are usually left to graze indiscriminately on infected pastures containing larvae or other developmental stages of these helminth parasites (Bukhari \& Sanyal, 2011). This indiscriminate grazing practice also has deleterious effects on the environment which has to be maintained at equilibrium for the whole good of man and animals.

Deworming programs: The lack of proper organization and implementation of deworming programs and availability of viable and efficacious anthelmintics has also plagued the livestock industry in developing countries (Fukumoto, 1998). In addition to this many farmers are ignorant of the crucial role of strategic deworming programs in livestock. Strategic deworming programs will reduce the worm burden in livestock and maximize the productivity of the animals in addition to ensuring the protection of other animals and humans from helminths of zoonotic importance which can be easily transmitted from animals to man or vice-versa.

Inadequate Practical and result oriented research: Researches should also aim at solving problems in the community and society and should be well funded. But this is not the case in many of the developing countries of the world where researches are mostly mere academic exercises with little practical relevance to the needs of the farmer who is looking for a solution to his livestock problems. Researches should be geared towards the production of vaccines against Helminthosis. In addition to research on the production of vaccines, it may be worthwhile to investigate the possibility of production of highly helminth resistant animals.

The government: The political leadership in developing countries plays a very crucial role in the livelihood of the people and in the decisions they take. When governments set up committees to proffer solutions to certain livestock problems but fail to implement the recommendations of those committees, many farmers get frustrated and the development of the livestock industry is hampered with. One of the major differences between the developed and developing countries is the enactment and implementation of policies for the common good of the citizenry.

\section{The control of Helminths}

Strategies for control of helminth parasites begin with a good understanding of the life-cycle of the helminth parasite. Helminth parasites come in three major classifications namely cestodes (tapeworms), nematodes (round worms) and trematodes (flukes) (Tibbo, et al., 2011). Various methods of controlling helminths that are currently in use and some of which will be more useful and relevant in future have been proposed by Gronvold et al (1993) divided into 2 major groups which include:

1. Chemical control such as chemotherapy, use of poison, use of repellant and pheromones.

2. Non-Chemical control such as biological control, worm vaccines, selection for host resistance, grazing management, nutritional management, interspecific competition and male sterile technique.

\section{Chemical Control}

Chemotherapy: Control of the larval stages will ensure that the parasite's developmental cycle is broken. The breaking of the parasites life cycle can be achieved by the use of suitable anthelminthic drugs such as Levamisole Hydrochloride and various Benzimidazoles, many of which also act on the adult stages of the parasite (Sargison, 2011).

Table-1. Some drugs used in the treatment of helminths in livestock

Nematodes (Roundworms)

Benzimidazoles

Ivermectin

Levamisole

Pyrantel

Piperazine

Emodepside

Halogenated Salicylamides

Closantel

Levamisole

Cestodes (Tapeworms)

Benzimidazoles

Niclosamide

Trematodes (Flukes)

Praziquantel

Closantel

Triclabendazole

Nitroxynil

Anthelmintics used to control helminths fall in 3 major categories:

Group-1. BZ are the benzimidazoles or "white drenches"

Group-2. LM includes levamisole and morantel

Group-3. ML are the macrocyclic lactones, which include doramectin, ivermectin and moxidectin 
One of the greatest concerns of helminthologists in recent times is the issue of drug resistance which implies that certain drugs can no more be used in certain livestock. Chemical residues in food are a cause for concern for the future. Residues are a major point of concern for anthelmintics. Certain Benzimidazoles and their prodrugs are known teratogens. The situation is even getting more disturbing with the advent of multiple drug resistance (Murphy, et al., 2006; Sargison, 2011).

Other forms of Chemical Control: The use of poisons, repellants and pheromones to control helminths has also been practiced in livestock with varying results and levels of efficacy (De \& Sanyal, 2009; Knowles, 2011; Sargison, 2011).

\section{Non-Chemical Control}

Biological control: Biologic control can be natural or applied. Certain organisms such as some Fungi are known to attack and destroy helminths for example Arthobotrys spp. (A. oligospora) and Monacrosporium spp. have been tested for biological control agents (De \& Sanyal, 2009).

Grazing management: Apart from the use of drugs, there are husbandry practices and measures that are essential for control of helminth parasites. Farmers should avoid early morning grazing so that the animals do not take in the infective larvae of the parasite from the pasture. When the sun rises is the best time to take the animals for grazing. Rotational and zero grazing of the animals should also be carefully planned and carried out to maximize pasture consumption and encourage immunity of the animal as well as maximizing productivity (Bukhari \& Sanyal, 2011).

Worm vaccines: There are attempts to produce vaccines against worms in animals and humans. About 2 billion people are infected with helminths worldwide. Work in this area is still under research even though some level of success has been achieved (Harris, 2011).

Host resistance selection: Certain breeds and species of animals are more resistant to helminths than others. Based on this a selection procedure should be used.

Other Non-chemical methods: There are other methods that can be used to control Helminthosis which includes nutritional management, interspecific competition and male sterile technique. The best method varies from one farm to another and the expertise of the personnel involved.

\section{Conclusion}

In order to achieve control of Helminthosis in developing countries an integrated approach towards helminth control, adequate funding of parasite control programs, education of farmers on control strategies and eradication of poverty must be pursued with all diligence by the governments and relevant authorities. Anything short of this means the livestock industry will continue to suffer great economic losses through Helminthosis.

\section{References}

1. Adekunle, O. A., Oladele, O. I., \& Olukaiyeja, T. D. (2002). Indigenous control methods for pests and diseases of cattle in Northern Nigeria Livestock Research for rural development, 14(2).

2. Aragaw, K., Teferi, M., Haile, A., \& Tibbo, M. (2010). Effects of strategic helminthosis control on age at first lambing and lambing interval of communally grazed Menz ewes in Ethiopia. Livestock Science, 135(1), 38-43.

3. Brundson, R. V. (1980). Principles of helminth control. Veterinary Parasitology, 6:185-215.

4. Bukhari, S., and Sanyal, P. K. (2011). Epidemiological Intelligence for Grazing Management in Strategic Control of Parasitic Gastroenteritis in Small Ruminants in India - A Review. Vet. World, 4(2), 92-96.

5. Chavan, P. B., Khan, L. A., Raut, P. A., Maske, D. K., Rahman, S., Podchalwar, K. S., et al. (2008). Prevalence of Nematode parasites of Ruminants at Nagpur. Vet. World, 1(5), 140.

6. Chitra, R., Rajendran, S., Prasanna, D., \& Kirubakaran, A. (2011). Influences of age on the prevalence of Parasitic infections among donkeys in Erode district, Tamilnadu, India. Vet. World, 4(6), 258-259. 
7. De, S., \& Sanyal, P. K. (2009). Biological Control of Helminth Parasites by Predatory Fungi. VetScan, 4(1).

8. Donald, A. D. (1985). New methods of drug application for control of Helminths. Veterinary Parasitology, 18(2), 121-137.

9. Esrony, K., Kambarage, D. M., Mtambo, M. M. A., Muhairwa, A. P., \& Kusiluka, L. J. M. (1997). Helminthosis in local and cross-bred pigs in the Morogoro region of Tanzania. Preventive Veterinary Medicine, 32(1-2), 41-46.

10. Fukumoto, S. I. (1998). Gastro-intestinal helminthosis in domestic animals - control strategies in japan. Parasitology International, 47(Supplement 1), 39-39.

11. Gronvold, J., Wolstrup, J., Nansen, P., Henriksen, S. A., Larsen, M., \& Bresciani, J. (1993). Biological control of nematode parasites in cattle with nematode-trapping fungi: a survey of Danish studies. Vet Parasitol, 48(1-4), 311325.

12. Harris, N. L. (2011). Advances in helminth immunology: optimism for future vaccine design? Trends in Parasitology, 27(7), 288-293.

13. Ibrahim, M. A., Nwude, N., Aliu, Y. O., \& Ogunsusi, R. A. (1983). Traditional concepts of disease and treatment among Fulani herdsmen in the Kaduna State of Nigeria. ODI Pastoral Network Paper 6 C.

14. Knowles, S. C. L. (2011). The effect of helminth co-infection on malaria in mice: A metaanalysis. International Journal for Parasitology, In Press, Accepted Manuscript.

15. Lanusse, C. E., \& Prichard, R. K. (1993). Relationship between pharmacological properties and clinical efficacy of ruminant anthelmintics. Veterinary Parasitology, 49(2-4), 123-158.

16. Moore, L. S. P., \& Chiodini, P. L. (2010). Tropical helminths. Medicine, 38(1), 47-51.

17. Murphy, T. M., Fahy, K. N., McAuliffe, A., Forbes, A. B., Clegg, T. A., \& O'Brien, D. J. (2006). A study of helminth parasites in culled cows from Ireland. Preventive Veterinary Medicine, 76(1-2), 1-10.

18. P.Mirajkar, P., Kumar, S., \& Y.P.Singh (2011). Preference of service providers for the veterinary service-a case study of Sangli District of Maharastra state, India. Vet. World, 4 (3), 106-108.

19. Reddy, M. S., \& Rao.B, S. (2011). Relationship between Affordability to pay for the Veterinary Services and profile characteristics of Dairy farmers. Vet. World, 4(6), 266-268.

20. Reinecke, R. K. (1980). Chemotherapy in the control of helminthosis. Veterinary Parasitology, 6(1-3), 255-292.

21. Roepstorff, A., Mejer, H., Nejsum, P., \& Thamsborg, S. M. (2011). Helminth parasites in pigs: New challenges in pig production and current research highlights. Vet. Parasitol., 180(1-2), 72-81.

22. Sargison, N. D. (2011). Pharmaceutical Control of Endoparasitic Helminth Infections in Sheep. Veterinary Clinics of North America: Food Animal Practice, 27(1), 139-156.

23. Schantz, P. M. (1987). Changing patterns of parasitic disease: Old enemies and new invaders--the battle wages on. International Journal for Parasitology, 17(2), 697-710.

24. Tembely, S., Lahlou-kassi, A., Rege, J. E. O., Sovani, S., Diedhiou, M. L., \& Baker, R. L. (1997). The epidemiology of nematode infections in sheep in a cool tropical environment. Veterinary Parasitology, 70 (1-3), 129-141.

25. Tibbo, M., Aragaw, K., Teferi, M., \& Haile, A. (2011). Effect of strategic helminthosis control on mortality of communally grazed Menz lambs of smallholders in the cool central Ethiopian highlands. Small Ruminant Research, 90(1-3), 58-63.

26. Tisdell, C. A., Harrison, S. R., \& Ramsay, G. C. (1999). The economic impact of endemic diseases and disease control programs. Rev. Sci. Tech. (OIE), 18(2), 380-398. 